\title{
Salmon Muscle Adherence to Polymer Coatings and Determination of Antibiotic Residues by Reversed-Phase High-Performance Liquid Chromatography Coupled to Selected Reaction Monitoring Mass Spectrometry, Atomic Force Microscopy, and Fourier Transform Infrared Spectroscopy
}

\author{
E. Zumelzu, ${ }^{1}$ M. J. Wehrhahn, ${ }^{1}$ O. Muñoz, ${ }^{1}$ and F. Rull ${ }^{2}$ \\ ${ }^{1}$ Institute of Materials, Biochemistry and Food Science, University Austral of Chile, P.O. Box 567, 5111187 Valdivia, Chile \\ ${ }^{2}$ Department of Condensed Matter Physics, University of Valladolid, 47002 Valladolid, Spain
}

Correspondence should be addressed to E. Zumelzu; ezumelzu@uach.cl

Received 21 September 2015; Revised 18 November 2015; Accepted 25 November 2015

Academic Editor: Alenka Vesel

Copyright (C) 2015 E. Zumelzu et al. This is an open access article distributed under the Creative Commons Attribution License, which permits unrestricted use, distribution, and reproduction in any medium, provided the original work is properly cited.

The persistent adhesion of salmon muscle to food container walls after treatment with urea solution was observed. This work evaluated the diffusion of antibiotics from the salmon muscle to the polyethylene terephthalate (PET) coating protecting the electrolytic chromium coated steel (ECCS) plates. New aquaculture production systems employ antibiotics such as florfenicol, florfenicol amine, oxytetracycline, and erythromycin to control diseases. The introduction of antibiotics is a matter of concern regarding the effects on human health and biodiversity. It is important to determine their impact on the adhesion of postmortem salmon muscle to can walls and the surface and structural changes affecting the functionality of multilayers. This work characterized the changes occurring in the multilayer PET polymer and steel of containers by electron microscopy, 3D atomic force microscopy (3D-AFM), X-ray photoelectron spectroscopy (XPS), and Fourier transform infrared spectroscopy (FT-IR) analyses. A robust mass spectrometry methodology was employed to determine the presence of antibiotic residues. No evidence of antibiotics was observed on the protective coating in the range between 0.001 and $2.0 \mathrm{ng} / \mathrm{mL}$; however, the presence of proteins, cholesterol, and alphacarotene was detected. This in-depth profiling of the matrix-level elements is relevant for the use of adequate materials in the canning export industry.

\section{Introduction}

Aquacultural use of antimicrobials in developed countries has generally been restricted to avoid potential selection for human pathogens resistant to antimicrobials effective in clinical practice [1-7]. The most relevant negative effect of antibiotics is that of antimicrobial resistance (AMR), which threatens the effective prevention of an ever-increasing range of infections. Of the ingested antimicrobials, approximately $80 \%$ pass into the environment in unabsorbed form in feces or after absorption, in secreted forms in urine, and other secretions $[8,9]$. We state that part of the antibiotics absorbed by the salmon muscle is diffused to the PET polymer coating affecting its recycling capacity as ecomaterial in the fish canning industry and altering its microstructure and functionality designed to preserve the organoleptic properties of food. Salmon muscles are biopolymers composed of proteins, which are molecules formed by linear long chains of monomeric building blocks strung together by peptide bonds between adjacent carbonyl $(-\mathrm{COOH})$ and amino $\left(-\mathrm{NH}_{2}\right)$ acid residues.

Color of salmonid flesh is due to dietary carotenoids, mainly astaxanthin and canthaxanthin, which fish cannot synthesize de novo. In the wild, trout utilize carotenoids from their prey, while, under culture conditions, these compounds are added to the diet [10]. 
Because carotenoids contain a system of conjugated carbon-carbon double bonds they are sensitive to oxidation, which generally causes their bleaching [11]. In a supermarket where fish are offered in attractive and ready-to-cook units, color is one of the major attributes that affect the consumer perception of quality [12]. Visual appearance is often the only criterion on which the consumer has to base its selection of fish purchase.

In addition, an important aspect in salmon packaging is the production of energy in the postmortem muscle, where the oxygen supply to the muscle tissue is interrupted and then the energy production is restricted. The glycogen (storage carbohydrate) or fats are oxidized in a series of reactions which finally produce carbon dioxide $\left(\mathrm{CO}_{2}\right)$, water, and adenosine triphosphate (ATP). Such release generally tends to produce chemical changes in the industrial molecules and is strongly related to the crystallinity of polymers; thus, if extreme conditions occur, they may lead to the degradation of PET polymer coatings [13-16].

To ensure sufficient shelf-life, canned food is heat-treated by steam, steam-air mixtures, water, or spraying water. The coldest spot in the can is used as the reference point to determine whether the cans have received an adequate heat treatment or not. The heat treatment should ensure the inactivation of microorganisms that cause food poisoning and spoilage. The amount of heating needed in the coldest spot in the packaged food is in the range $4-12 \mathrm{~min}$ at $121^{\circ} \mathrm{C}$ for some typical canned food products [18-20]. As a consequence of this heat treatment, some packed products can partly adhere to the can wall. Minimization of the amount of product adhering to the can wall after emptying of the can is one of the convenience requirements of consumers.

Bistac et al. [21] found several factors that affect mackerel adhesion to lacquered can walls. The reported effects clearly indicate that proteins are the major cause of this adhesion. Proteins consist of chains of covalently bound amino acids. Four types of bonds can be formed between the amino acids residues: covalent, electrostatic, hydrogen, and hydrophobic bonds. These bonds are responsible for the structure of the native protein [22].

Antibiotics play an important role in large-scale commercial fish farming and have been a key reason for the success of salmon cultivation. Pharmaceutical companies have performed a considerable amount of research on fish vaccines; however, limited information is available in scientific publications [23]. Antibiotics applied as medication may have an effect on salmon adhesion to the can walls. It is not clear whether their excessive use causes them to be absorbed by the PET polymer or otherwise remain in the fish muscle. Therefore, the use of low-scale techniques to determine and characterize salmon adhesion to the container wall, as well as the possible diffusion of antibiotics to the PET coating and their effects on performance, is the main objectives of this study. Hence, an innovative methodology consisting of reversed-phase high-performance liquid chromatography (HPLC) coupled to selected reaction monitoring (SRM) mass spectrometry was employed. Depending on the antibiotic, the detection range in solution is between 0.001 and $2.0 \mathrm{ng} / \mathrm{L}$, a value far below the limit allowed in cultured fish as that observed for chloramphenicol with less than $0.3 \mathrm{mg} / \mathrm{kg}$ [24].

Moreover, there is a growing concern for the conservation of ecosystems given the high amount of unmetabolized antibiotic substances passed into the aquatic environment in salmon aquaculture systems, where the water and sediment concentrations of chloramphenicol have been found to be $112.3 \mathrm{ng} / \mathrm{L}$ and $0.1957 \mathrm{mg} / \mathrm{kg}$, respectively $[25,26]$.

The above analysis is complemented with characterization techniques such as electron microscopy and 3D-AFM and the evaluation of potential changes in the protective PET polymer by FT-IR spectroscopy.

Exposure of polymers to subtherapeutic antimicrobial concentrations may lead to adverse effects on their performance. Hence, the salmon industry requires the support of knowledge and the use of adequate characterization techniques to make their products meet the high standards of quality involving the employment of multilayer metal-polymer composites [17, 27-29].

\section{Materials and Methods}

The container in this study is made up of a multilayer composite no more than 200 microns in total thickness. It consists of low-carbon base steel protected by $200 \mathrm{~nm}$ thick chromium $\left(\mathrm{Cr}^{0}\right)$ and chromium oxide $\left(\mathrm{Cr}_{2} \mathrm{O}_{3}\right)$ layers to increase corrosion resistance and a surface polyethylene terephthalate polymer (PET) coating to prevent physicochemical interactions between the food and metal substrate [14].

This material is an ecoefficient, environmentally friendly, chromium VI-free (non-carcinogenic) metal-polymer. This thin, multilayered electrolytic chromium coated steel (ECCS) laminate protected by a polyethylene terephthalate (PET) coating is devoid of contaminants or chemical migration of substances to the medium such as bisphenol A (epoxy resins and polycarbonates), alkyl phthalates (plastifiers), and bisphenol A diglycidyl ether. In addition, these composites help to diminish the rate of coal emissions to the atmosphere, because of the absence of $\mathrm{CO}_{2}$ release, unlike that seen in lacquers during their curing stage $[30,31]$.

A set of 48 randomly chosen salmon cans, stored for 116 months and originating from antibiotic-treated farming cages, were analyzed in a joint working design between our research laboratories and an export canning company.

The standard manufacturing protocol was employed to produce the cans and to determine the salmon adhesion to the PET coating on the container wall, as well as the morphological and chemical changes in the multilayers. Food cans were manufactured employing $50 \mathrm{~mL}$ of $2.5 \% \mathrm{NaCl}$ solution, sterilized at $120^{\circ} \mathrm{C}$ for 60 minutes, immersed in warm water bath in the range of $50-80^{\circ} \mathrm{C}$ prior to sterilization, and stored for one week at $20^{\circ} \mathrm{C}$ before opening. Samples showing evidence of muscle adhesion, even after strong shaking to empty the can, were selected.

Later, the removal of salmon muscle that adhered to the can walls was performed with $6 \mathrm{M}$ urea solution to form hydrogen bonds and unfold the proteins. 


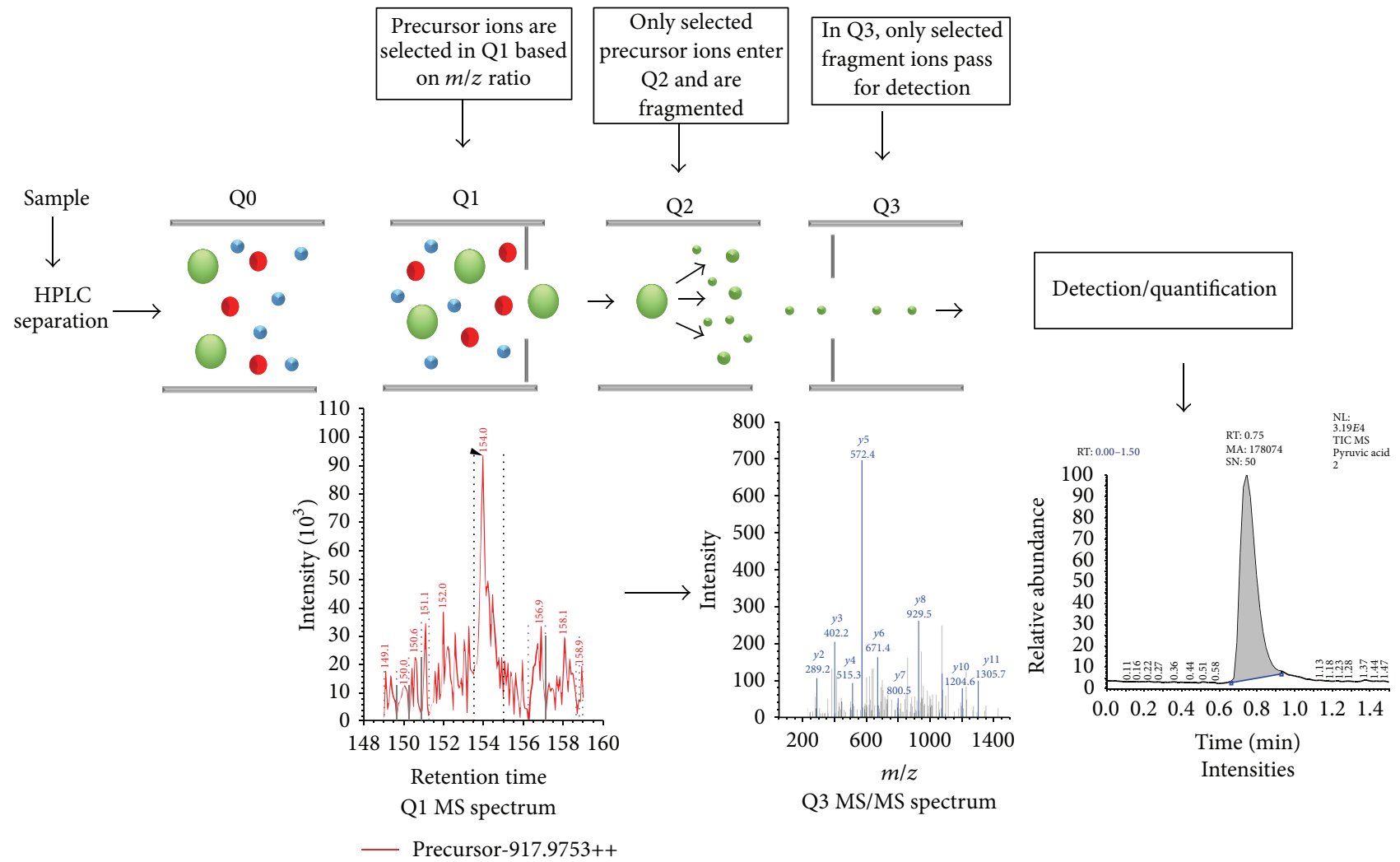

FIGURE 1: Schematics of a triple-stage quadrupole mass spectrometry performing a SRM analysis.

2.1. Characterization of Salmon Muscle Adhesion. The surface characterization of salmon adhesion on the PET polymer was carried out by scanning electron microscopy (SEM) using a LEO 400 series scanning electron microscope and 3D-AFM with a Nanoworld Pyrex-Nitride probe. The first $10 \mathrm{~nm}$ of the PET surface in contact with the salmon muscle was analyzed by XPS with a PerkinElmer Physical Electronics Division (PHI) 5100 spectrometer and a standard X-ray source in order to compare the performance in time between the control material and the stored cans exhibiting salmon adhesion and to detect the presence of hydrophobic organosilanes that protect the polymer. Samples $1 \times 2 \mathrm{~cm}$ in size were collected from a PET-coated ECCS plate previously cleansed with distilled water to remove any muscle remains. The samples were placed 24 hours in advance in a high vacuum chamber to prevent impurities and contaminants from affecting the equipment and to avoid working pressure changes in these highly sensitive analyses. A general analysis was performed on all specimens with measurements between 1200 and $0 \mathrm{eV}$ to detect the presence of undesired metal traces.

2.2. Determination of Antibiotics by Reversed-Phase HPLC. A robust method for the identification of multiple residues was implemented by reversed-phase HPLC coupled to a Thermo Scientific TSQ Vantage triple-stage quadrupole (TSQ) mass spectrometer to perform selected reaction monitoring, commonly referred to as SRM, in which a selected precursor ion associated to a compound of interest is collision-induced dissociated to analyze its fragments as shown in Figure 1.

This method has been used to quantify a number of molecules of interest since it allows the detection of metabolites in very small amounts of the order of picograms and even femtograms; therefore, it can be considered an extremely sensitive technique for monitoring molecules of biological interest. Hence, its application in the salmon industry for the quantification of trace levels of antibiotics is a practical analytical method worthy of concern.

2.2.1. Sample Extraction. The plates collected from the samples were incubated for $24 \mathrm{~h}$ at $-20^{\circ} \mathrm{C}$ in $5 \mathrm{~mL}$ methanol of liquid chromatography-mass spectrometry (LC-MS) grade. Then, the plates were removed from the containers and stored; the supernatant was dried in a SpeedVac centrifugal evaporator for its later reconstitution in $300 \mu \mathrm{L}$ methanol with $0.1 \%$ formic acid (v/v).

2.2.2. LC-MS Analysis. The samples were submitted to reversed-phase chromatography using the HPLC column Syncronis C18, particle size $1.7 \mu \mathrm{m}, 50 \times 2.1 \mathrm{~mm}$, and a gradient from 0 to $100 \%$ of $0.1 \%$ formic acid in water (v/v) to $0.1 \%$ formic acid in methanol (v/v) for $10 \mathrm{~min}$ on a Dionex 3000 UHPLC chromatograph equipped with a Thermo Finnigan TSQ Vantage triple-stage quadrupole (TSQ) MS/MS detector for the quantification by SRM. 
TABLE 1: Values employed in the antibiotic analyses by SRM.

\begin{tabular}{|c|c|c|c|c|c|}
\hline Antibiotic & Precursor ion $(m / z)$ & Product ion $(m / z)$ & Polarity & Collision energy (V) & CID gas (mTorr) \\
\hline \multirow{2}{*}{ Florfenicol } & \multirow{2}{*}{356} & 185 & \multirow{2}{*}{-} & \multirow{2}{*}{30} & \multirow{2}{*}{0.5} \\
\hline & & 336 & & & \\
\hline \multirow{2}{*}{ Oxytetracycline } & \multirow{2}{*}{461} & 425 & \multirow{2}{*}{+} & \multirow{2}{*}{25} & \multirow{2}{*}{1.0} \\
\hline & & 442 & & & \\
\hline \multirow{2}{*}{ Erythromycin } & \multirow{2}{*}{734} & 157 & \multirow{2}{*}{+} & \multirow{2}{*}{20} & \multirow{2}{*}{1.0} \\
\hline & & 575 & & & \\
\hline \multirow{3}{*}{ Chloramphenicol } & \multirow{3}{*}{320} & 152 & \multirow{3}{*}{-} & \multirow{3}{*}{12} & \multirow{3}{*}{1.1} \\
\hline & & 194 & & & \\
\hline & & 257 & & & \\
\hline \multirow{2}{*}{ Florfenicol amine } & \multirow{2}{*}{248} & 130 & \multirow{2}{*}{+} & \multirow{2}{*}{20} & \multirow{2}{*}{1.5} \\
\hline & & 230 & & & \\
\hline
\end{tabular}

TABLE 2: Detection limits for each antibiotic by SRM.

\begin{tabular}{lcc}
\hline Antibiotic & $\begin{array}{c}\text { Lower detection limit } \\
(\mathrm{ng} / \mathrm{mL})\end{array}$ & $\begin{array}{c}\text { Upper detection limit } \\
(\mathrm{ng} / \mathrm{mL})\end{array}$ \\
\hline Florfenicol & 0.001 & 50 \\
Oxytetracycline & 0.1 & 500 \\
Chloramphenicol & 2 & 500 \\
Erythromycin & 2 & 500 \\
Florfenicol amine & 0.001 & 50 \\
\hline
\end{tabular}

The details of the precursor ions, as well as those of the product ions, and the conditions of the trial are detailed in Table 1.

The ionization conditions of the sample consisted of $4000 \mathrm{~V}$ at a capillary temperature of $380^{\circ} \mathrm{C}$, nitrogen pressure of $60 \mathrm{~L} / \mathrm{min}$, and auxiliary gas flow of $35 \mathrm{~L} / \mathrm{min}$.

The details of the detection limits for each antibiotic applied to farm-raised salmon for canning purposes are given in Table 2.

The florfenicol, florfenicol amine, oxytetracycline, and erythromycin standards were prepared from a stock solution at $1 \mathrm{mg} / \mathrm{mL}$ to be serially diluted to working solutions ranging from $50 \mathrm{ng} / \mathrm{mL}$ to $10 \mathrm{pg} / \mathrm{mL}$ in methanol for florfenicol and florfenicol amine and from $500 \mathrm{ng} / \mathrm{mL}$ to $100 \mathrm{pg} / \mathrm{mL}$ in methanol for erythromycin, oxytetracycline, and chloramphenicol.

2.2.3. Mass Spectrometry Data Analysis. Reversed-phase mass spectrometry was performed on a triple-stage quadrupole analytical column with a mass spectrum scan from 200 to $1500 \mathrm{Da}$, a resolution of $0.04 \mathrm{RFHM}$, and data collection speed of $0.5 \mathrm{~s}$.

The electrospray ionization (ESI) of the aerosol consisted of a capillary carrying a potential difference of approximately $4000 \mathrm{~V}$ at $380^{\circ} \mathrm{C}$, nitrogen pressure of $60 \mathrm{~L} / \mathrm{min}$, and the ion transfer heated to $350^{\circ} \mathrm{C}$.

In addition, $12.5 \%$ sodium dodecyl sulfate polyacrylamide gel electrophoresis (SDS-PAGE) was employed to denature the proteins of the residues on the PET surface that persisted after the urea solution treatment intending to remove them.
2.2.4. Electrophoresis under Denaturing Conditions (SDS$P A G E)$. The proteins in the samples were denatured with $12.5 \%$ sodium dodecyl sulfate polyacrylamide gel electrophoresis (SDS-PAGE) [32]. A gel with the following composition was used to separate the proteins effectively: $12.5 \%$ polyacrylamide (w/v), $0.375 \mathrm{M}$ tris- $\mathrm{HCl}, \mathrm{pH} 8.8$ buffer; $0.1 \%$ SDS (w/v); $0.03 \%$ ammonium persulfate $(\mathrm{w} / \mathrm{v})$; and $0.1 \%$ TEMED (v/v).

Once the separating gel had polymerized, a spacer gel was set on top having the following composition: $4 \%$ polyacrylamide (w/v), $0.125 \mathrm{M}$ tris- $\mathrm{HCl}, \mathrm{pH} 6.8$ buffer, $0.1 \%$ SDS $(\mathrm{w} / \mathrm{v}), 0.03 \%$ ammonium persulfate $(\mathrm{w} / \mathrm{v})$, and $0.1 \%$ TEMED $(\mathrm{v} / \mathrm{v})$. The proteins were solubilized in sample buffer with the following formulation: $62.5 \mathrm{mM}$ tris- $\mathrm{HCl}, \mathrm{pH} 6.8,1 \% \mathrm{SDS}$ $(\mathrm{w} / \mathrm{v}), 10 \%$ glycerol (v/v), 5\% $\beta$-mercaptoethanol (v/v), and $0.05 \%$ bromophenol blue (as marker of the ion front).

To facilitate the denaturation process, the samples were heated to $95^{\circ} \mathrm{C}$ for $5 \mathrm{~min}$. Then, the samples were migrated by applying a constant current of $25 \mathrm{~mA}$ until the ion front reached the bottom of the gel. The electrode buffer contained $25 \mathrm{mM}$ tris- $\mathrm{HCl}, 0.19 \mathrm{M}$ glycine, and $0.1 \%$ SDS (w/v). After electrophoresis, the gel was fixed with orbital shaking in 25\% isopropanol solution (v/v) and 10\% acetic acid (v/v) for 1 hour and then it was stained with $0.3 \%$ Coomassie blue R-250 solution (w/v), 30\% methanol (v/v), and 10\% acetic acid (v/v) for 1 hour. A distaining solution, which consisted of a mixture of $30 \%$ methanol (v/v) and $10 \%$ acetic acid, was employed to discolor the gel until the appearance of bands.

2.3. FT-IR Vibrational Spectroscopy. The changes in the multilayers were characterized by vibrational spectroscopy with a PerkinElmer Spectrum 100 FT-IR spectrometer supplied with a Universal ATR Sampling Accessory employing a DiComp crystal, which is composed of a diamond ATR with a zinc selenide $(\mathrm{ZnSe})$ focusing element which is in direct contact with the diamond. The spectral data were acquired at a resolution of $4 \mathrm{~cm}^{-1}$ and the number of accumulations was 8 . The analyses of the samples were made on several spots perpendicular to the PET surface where the salmon muscle was adhered and later removed with the urea solution treatment; $100 \%$ of the power was used to record the spectra. 


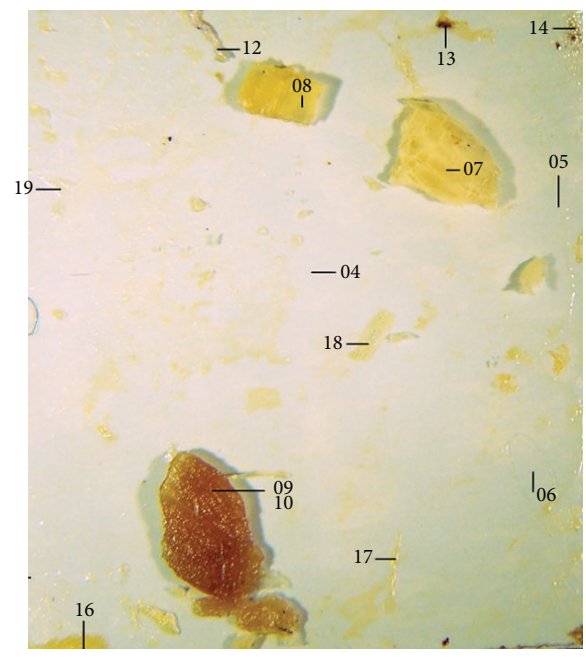

(a)

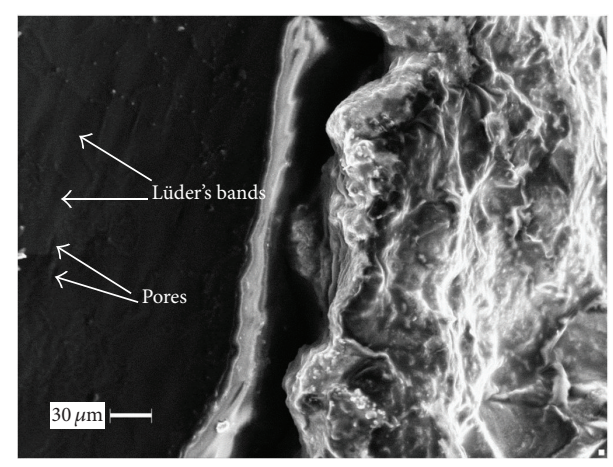

(c)

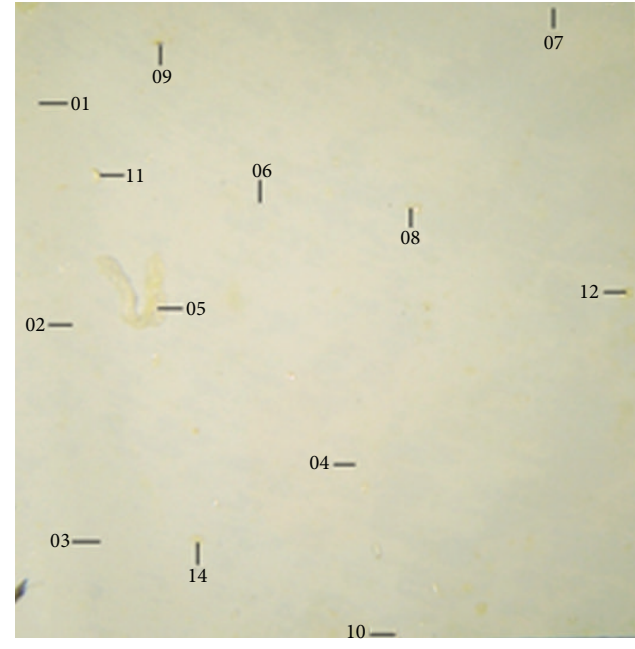

(b)

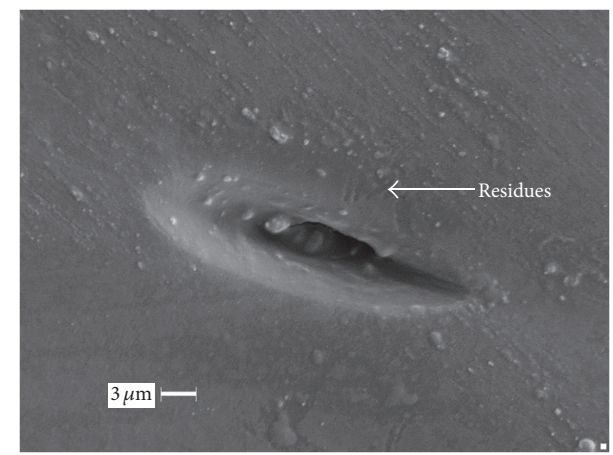

(d)

Figure 2: (a) The highest localized salmon adhesion occurred in samples stored for 16 months. It is possible to observe several zones of adhesion displayed in grey color of varied intensities. The white surfaces showed no evidence of changes on the PET coating $(\times 10)$. The lines and numbers correspond to points of spectroscopy analyses [17]; (b) PET polymer surface with small residues (grey) of salmon muscle that remained attached after the application of urea solution $(\times 10)$ [17]; (c) muscle morphology with peptide multilayers on PET surface with manufacturing defects (SEM); (d) muscle residues strongly adhered to the pore edge of the polymer coating posturea treatment (SEM).

\section{Results and Discussion}

The results obtained are concerned with the salmon muscle adhesion to the polymer-coated can walls after emptying the container and involved those areas of natural adhesion and later denaturing with urea solution.

Figure 2 (SEM) shows the morphology of salmon adhesion in samples with and without urea treatment. The salmon muscle adheres to the polymer coating and remains attached to the can wall. The salmon components may produce morphological changes that can be confused with the protein microstructure or amino acids adhered to the PET coating; Figure 2(a) shows part of the peptide multilayers with an irregular morphology. The polymer surface shows pores and Lüder's bands that originated during the deep drawing process of manufacturing favoring the adhesion of salmon muscle. On the other hand, Figure 2(b) shows residues of salmon muscle displaying a more regular muscle morphology (left) and strongly adhered to the pore edge by protein fibrils after the urea treatment. Next to it, it is also possible to see a pore with denatured proteins inside, which remained adhered to the polymer surface after the urea solution was applied. The pore size is of the order of 18 microns and originated during the manufacturing process of containers.

The adhesion is mainly characterized by two aspects: firstly, the chemical bond between the carbonyl group of the PET coating and the amino group of the salmon muscle proteins; and, in the second place, the surface condition of the protective polymer, by either the steel laminate orientation in the order of 45 degrees or the presence of defects such as pores and microcracks generated by the mechanical forming of the metal-polymer container.

The presence of isolated defects and the control of axial deformations occurring during the mechanical forming process minimize adhesion [33], since muscle adherence is a condition that follows the physicochemical interaction with the protective coating due to the eventual persistence of antibiotics and residues altering the functionality of the PET polymer. The characterization of the polymer through low dimension AFM observations made the phase changes and 

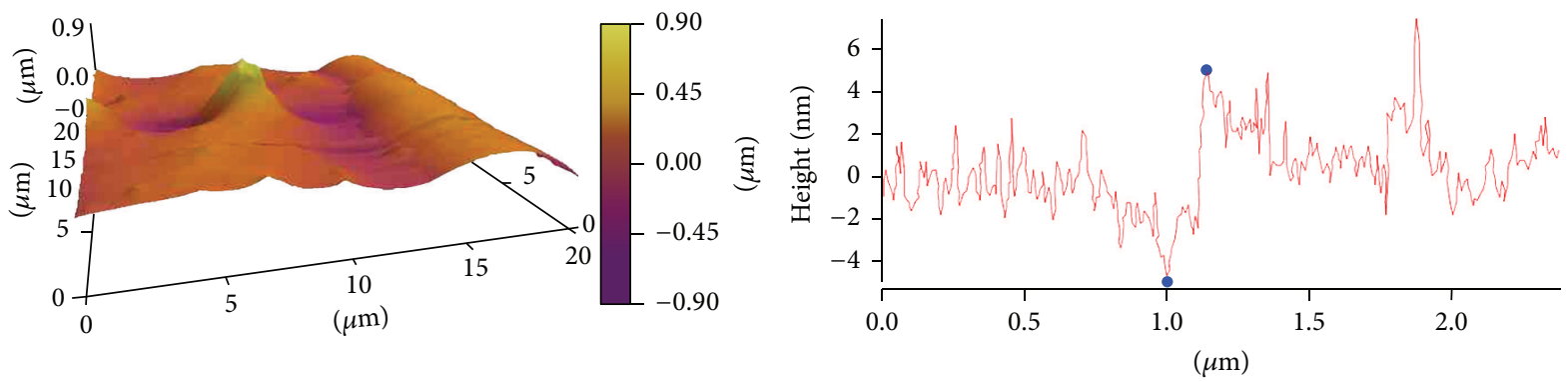

FIGURE 3: 3D-AFM characterization of PET surface topography and adhesion of salmon tissue residues.

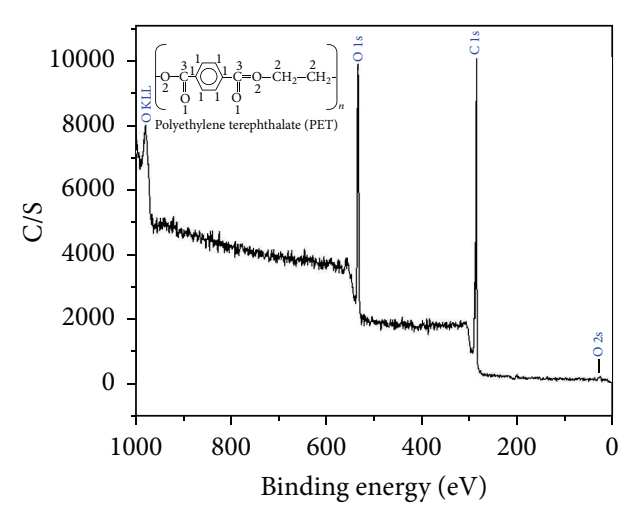

(a)

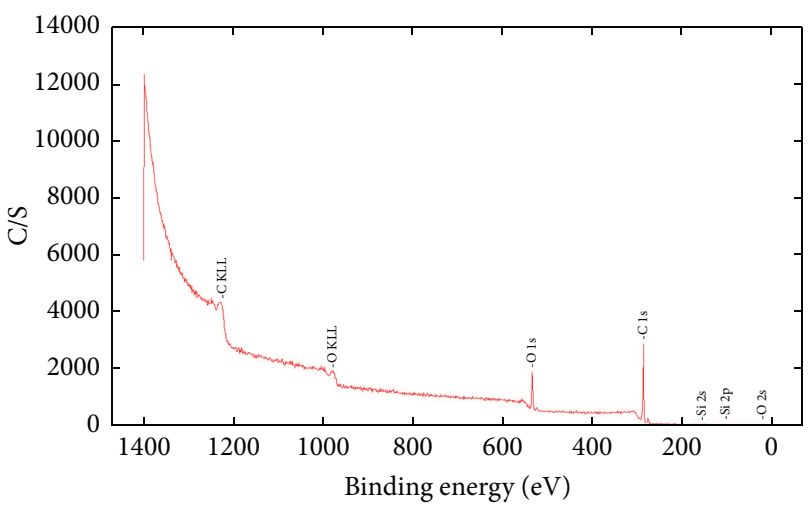

(b)

FIGURE 4: (a) XPS spectral analysis of PET surface from control samples before storage; (b) XPS spectral analysis of PET surface in microzones of salmon adhesion and removal.

the influence of the surface topography on the salmon muscle adhesion to the polymer evident. The 3D image of Figure 3 displays the muscle adhered to the surface; it also shows the well-marked roughness and the volume of tissue adhered to the PET surface structure.

These surface discontinuities favor adhesion of salmon muscle as suggested by the SEM observations in Figure 2. The AFM analyses show the phase changes in the $8 \mu \mathrm{m}$ zone, both with and without salmon adhesion detected at a nanometric level, thus changing the original surface condition of the protective polymer.

The 3D-AFM image of the PET polymer shows nanosized zones of salmon adhesion (protrusions) on the surface. This image represents the close interrelationship between the different materials and explains the presence of bonds resistant to urea as characterized by SEM. In a segment $8 \mu \mathrm{m}$ wide on the sample surface it is possible to detect the adhesion of salmon muscle residues with heights reaching $135 \mathrm{~nm}$; these residues generate morphology or texture changes at certain points on the polymer, facilitating possible physicochemical interactions due to the retention of material in the container wall.

Figure 4 depicts an XPS evaluation of the PET polymer surface in microzones where muscle adhesion to the polymer and later removal of the biopolymer (muscle) occurred, indicating the characteristic spectrum of PET as stated by NTIS [34]. The elements present, mainly oxygen and carbon, can be seen in the control and stored samples, showing small differences in their respective peaks. No evidence of nitrogen from the amino acids or proteins adhered to the PET surface was detected, given its location on the outer layer of the polymer which requires further modeling studies for its spectral detection. On the other hand, no presence of contaminants or elements from other layers were observed on the polymer surface, an aspect of importance since an organosilane-like protective layer was expected.

No presence of organosilane was detected by the spectral analysis. This compound is incorporated during the manufacturing of containers and provides a layer that turns them hydrophobic through the addition of additives like octadecylsilane (ODS- $\left.\mathrm{CH}_{3}\left(\mathrm{CH}_{2}\right)_{17} \mathrm{SiH}_{3}\right)$ that acts as a protective barrier to prevent the absorption of residues in solutions by the PET polymer structure [35]. From the above, it can be inferred that this would compromise the functionality of the coating and, if the polymer becomes degraded, it can also limit its recycling potential as ecomaterial. Since these phenomena occur during the storage of containers it is recommended to monitor them with techniques of higher spatial resolution.

The reversed-phase HPLC under the methodology employed in this study showed the presence of crystalline or translucent material after lyophilization of the samples (Figure 5), indicative of the isolation of some compound (or compounds) from the PET surface; the SEM characterization 

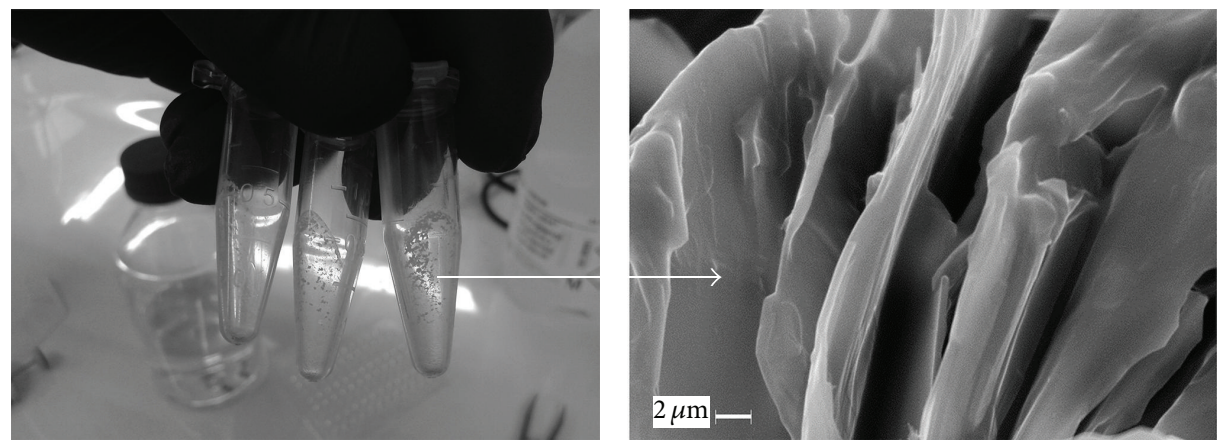

FIGURE 5: SEM morphology of crystalline amyloid protein on the PET coating surface.

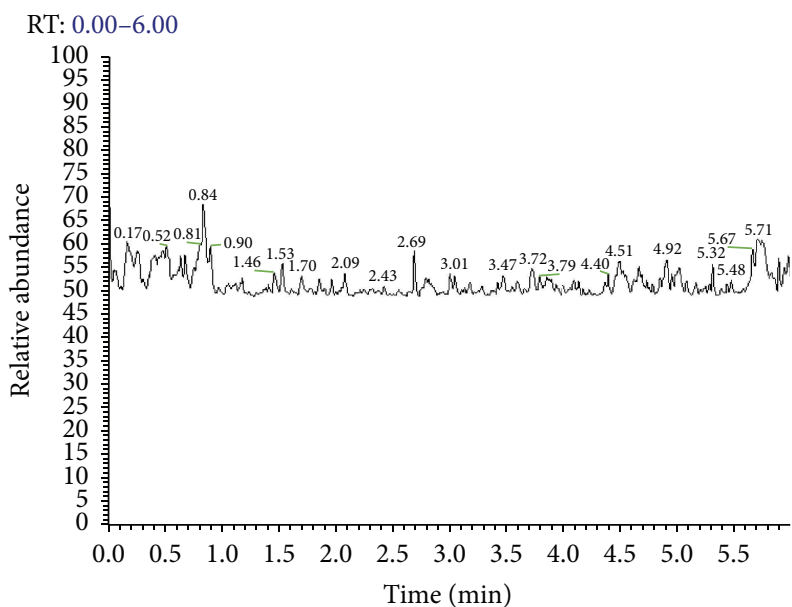

(a)

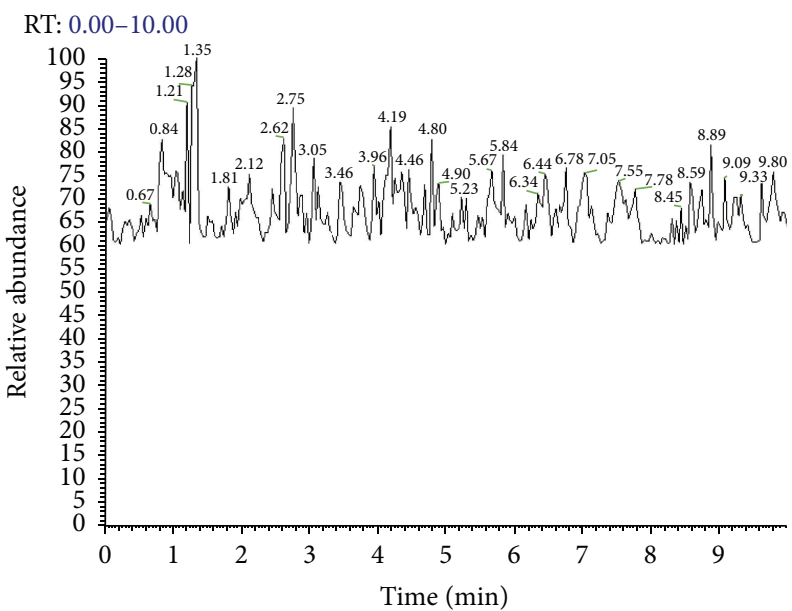

(c)

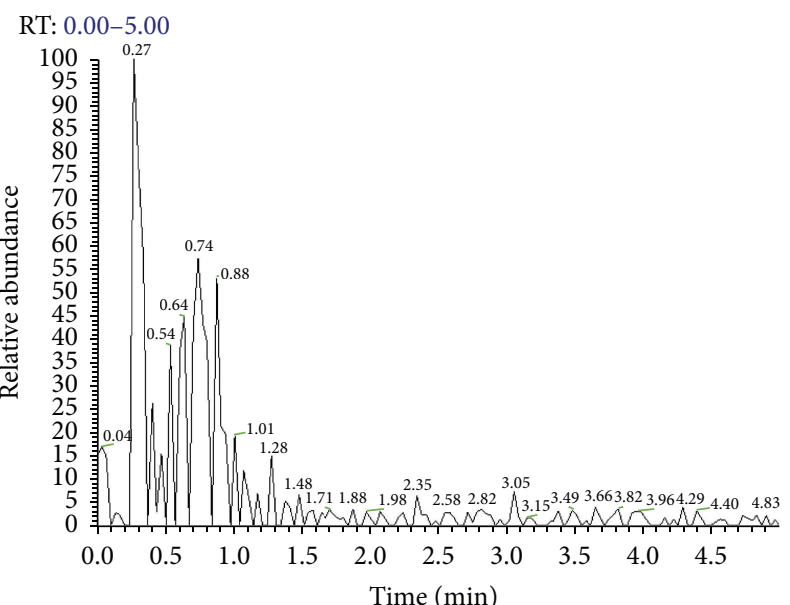

(b)

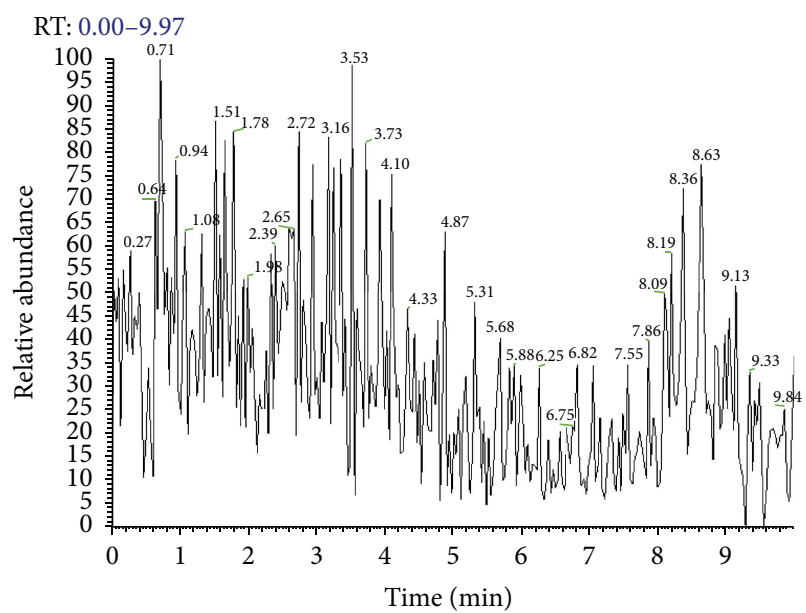

(d)

FIGURE 6: Chromatograms of quantifications of the various antibiotics in one of the samples. (a) Chloramphenicol; (b) erythromycin; (c) florfenicol and florfenicol amine; and (d) oxytetracycline.

indicated that this compound could be related to amyloid proteins from the salmon muscle.

Then these samples were resuspended in $200 \mu \mathrm{L}$ methanol to solubilize the crystals completely; this was followed by reversed-phase HPLC coupled to Thermo Scientific TSQ Vantage triple-stage quadrupole LC-MS/MS detector for
SRM quantification to deliver the highest sensitivity in the determination of the antibiotics florfenicol, florfenicol amine, chloramphenicol, oxytetracycline, and erythromycin. No presence of these antibiotics was detected in the samples analyzed in addition of their respective biological replicates (Figure 6). 
<smiles>CC1=C(/C=C/C(C)=C/C=C/C(C)=C/C=C/C=C(C)/C=C/C=C(C)/C=C/C2=C(C)CCCC2(C)C)C(C)(C)CCC1</smiles><smiles>CC(C)CCCC(C)C1CCC2C3CC=C4CC(=O)CCC4(C)C3CCC12C</smiles>

Cholesterol
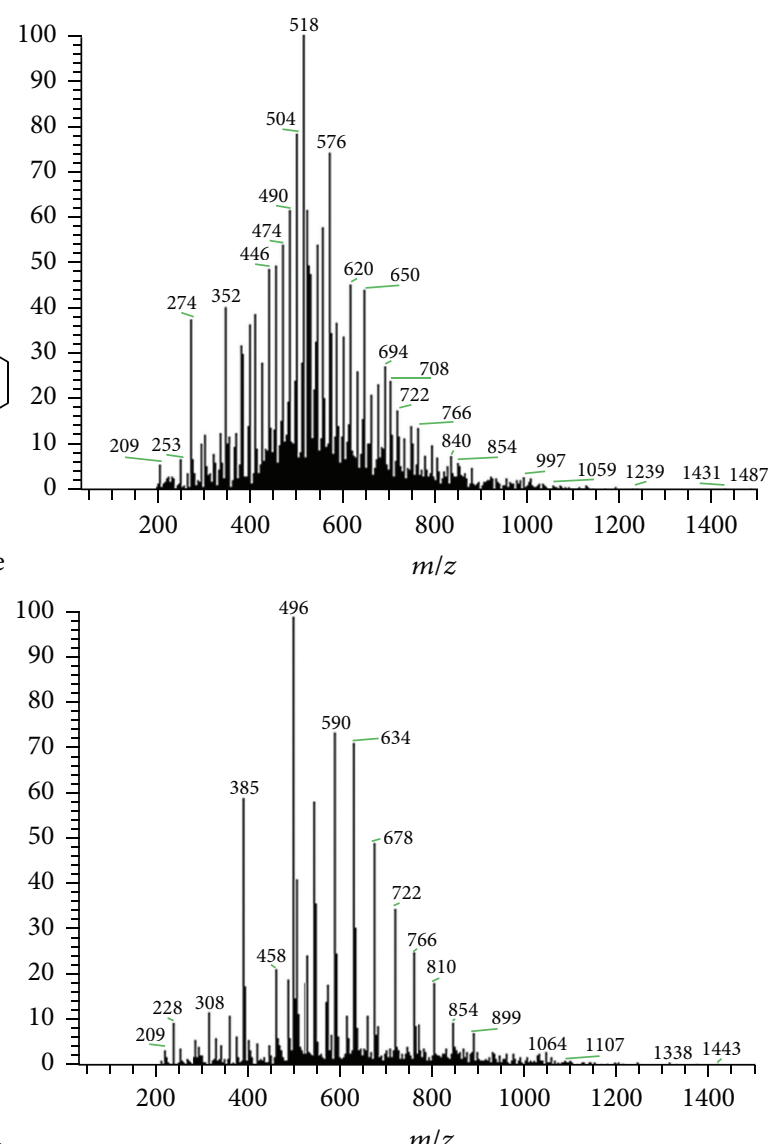

FIGURE 7: Spectral analysis and identification of compounds from the samples. Spectra in the NIST database match those of $\alpha$-carotene and cholesterol.

When the samples are positive, the chromatograms show two well-defined peaks [24, 36-38] with their characteristic retention times for each antibiotic. In this particular case, none of the samples showed the presence of these characteristic peaks; oppositely, a symmetrical baseline without the presence of peaks was evident.

It must be noted that the technique used for the quantification is based on the isolation of one precursor ion from the antibiotic; later, this ion is collision-induced dissociated (CID) and its fragments are analyzed in the second quadrupole to confirm the presence of the antibiotic by identifying at least two product ions, having whereby a high degree of certainty for the displayed data.

The crystals were resuspended again for the identification of molecules by mass spectrometry. For this purpose, the samples were submitted to reversed-phase HPLC to perform a spectral analysis considering a mass range between 200 and $1500 \mathrm{Da}$ to have a better perspective of the molecules to be found. The presence of several organic compounds was detected. The data indicated that some of the peaks corresponded to cholesterol and $\alpha$-carotene. This was determined by comparison of the spectra obtained from the database of mass spectra at the National Institute of Standards and Technology (NIST) (Figure 7), indicating 100\% certainty for $\alpha$-carotene; these molecules could have been transferred to the surface through direct contact between the content of the food can and the PET coating under study.

3.1. Influence of Cholesterol and Carotenes on PET. Cholesterol is a natural organic molecule $\left(\mathrm{C}_{27} \mathrm{H}_{46} \mathrm{O}\right)$ produced by cells. Variations in time in the amount of polyunsaturated fatty acids (PUFAs) and in the formation of oxysterols have been reported in canned products [39]. This work states that the correlation between the decrease in PUFAs and the increase in oxysterols accounts for the existence of a common mechanism of oxidation. Oxysterols, oxidized derivatives of cholesterol, are formed when raw materials or end products containing cholesterol are submitted to thermal treatments, oxidizing agents, or other physical and/or chemical conditions. This is in line with the treatment of canned salmon; however, given the results obtained from the above HPLC tests, further analyses evaluating whether the peptides adhered to the PET polymer can contribute to the structural protection of the polymer are required.

Moreover, the presence of $\alpha$-carotene on the PET surface may also need further analyses especially when considering the chemical interaction with the coating. It has been shown [40] that other carotenoids such as astaxanthin, responsible for the color of salmon flesh, are good antioxidants; that is, these are substances that can scavenge free radicals. The 


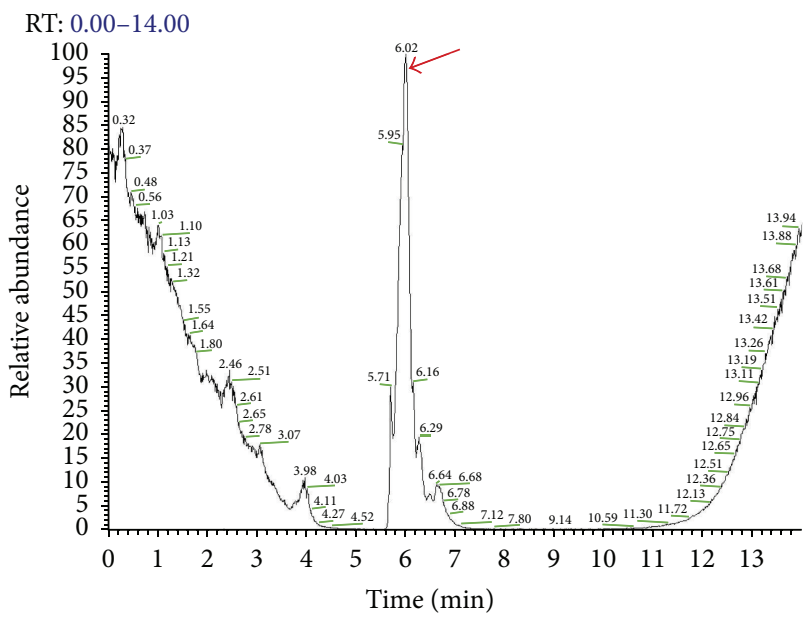

FIGURE 8: Mass spectrum peak with retention time of $3.96 \mathrm{~min}$; the molecular weight by deconvolution was estimated to be $8249.94 \mathrm{Da}$.

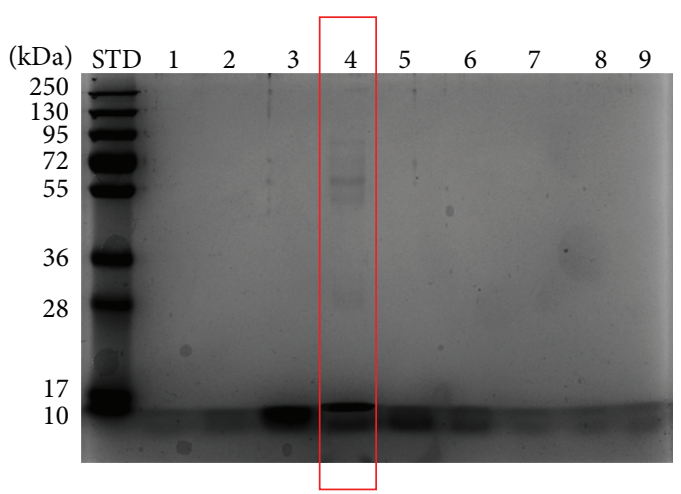

FIGURE 9: 12.5 SDS-PAGE run on samples and displaying peptides and proteins in lanes; STD is the molecular weight standard.

antioxidant activity of these pigments depends on a number of factors such as their chemical structure (size, number of substituents, cis-trans isomerism, etc.), concentration, partial pressure of oxygen, or interaction with other antioxidants. The presence of molecules of high molecular weight, such as $8249.94 \mathrm{Da}$ and $10836.04 \mathrm{Da}$ with retention times of 3.96 and $6.02 \mathrm{~min}$, was also observed, indicating the presence of proteins and peptides since they have a characteristic pattern of multiple electrical charges (Figure 8).

$12.5 \%$ SDS-PAGE was performed due to the detection of proteins of high molecular weight; thus, $10 \mu \mathrm{L}$ of each sample was loaded into each well to validate the presence of proteins in the samples, whereby each sample and its biological replicates were subjected to electrophoretic separation and the gel was stained with Coomassie blue solution. The presence of peptides was observed in all lanes and protein was detected in lane 4 (Figure 9). The lanes of protein bands ranging from $100 \mathrm{Da}$ to $10 \mathrm{kDa}$ are clearly visible in Figure 9.

Reversed-phase HPLC with a high sensitivity to detect chemical compounds showed no residues of antibiotics; the prolonged adhesion of salmon muscle to the PET polymer did not facilitate surface absorption; also, no evidence of

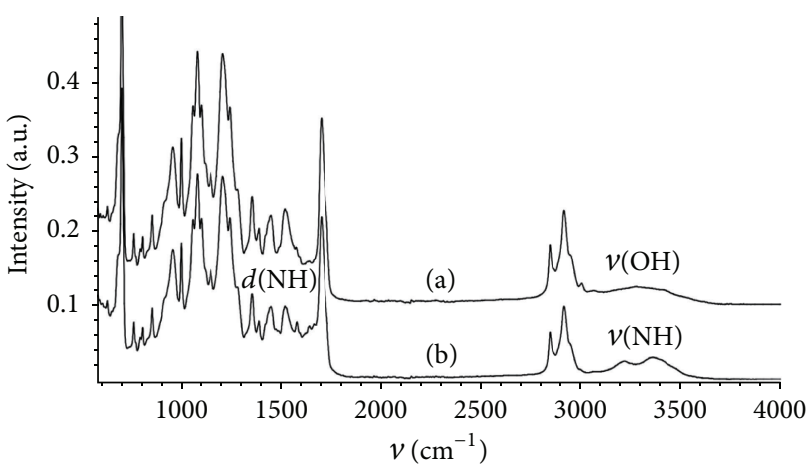

FIGURE 10: FT-IR spectra from areas showing reduced degradation (a), M1 and M2, when compared with PET controls (b), 1 and 2.

the presence of the ODS monolayer coating was observed, which has a hydrophilic protective function and prevents the absorption of compounds [41]. However, it was possible to identify the presence of peptides and proteins, which correlates well with the observations by SEM and AFM at a micro- and nanometer level, respectively.

Liquid chromatography (LC) and liquid chromatography-mass spectrometry (LC-MS) were used for the analysis of florfenicol in presence of its two identified degradation products (thiamphenicol and chloramphenicol). The drug showed instability in acidic, alkaline, and photolytic stress conditions mainly in solution-state form [36]. This could be consistent with canned salmon muscle, for which we have determined that the lactic acid $\mathrm{pH}$ values vary from 3.5 to 5.0 depending on the degree of freshness, facilitating therefore the instability of degraded or residual antibiotics, and even though antibiotics may remain in the muscle adhered to the PET they have no capacity to migrate or bind to the polymer.

This same technique was employed for the determination of oxytetracycline in salmon tissue [37], showing high linearity with respect to the desired limit; however, no detection was accomplished in the protective polymer of containers, since the antibiotic was extracted from the muscle.

Studies to assay erythromycin in medicated salmonid fish feed represented as pellets have been carried out by liquid chromatography and spectroscopy [38], having detected the antibiotic in band $3500 \mathrm{~cm}^{-1}$; however, no trials have been performed to follow its presence in fish muscles and its transference to the protective polymer of containers hence reflecting the originality of this study.

Figure 10 shows the FT-IR spectra of the analyses to characterize and validate the presence of compounds from the salmon tissue to the PET polymer, regarding the collection of additional information on the adhesion of salmon muscle and its eventual effects on the coating due to the presence of antibiotic residues. The spectra of several degraded areas related with the adherence of salmon tissues are compared with those of nondegraded zones. The upper M1 and M2 spectra belong to muscle-adhered and urea-treated samples, respectively, whereas the two lower spectra are from control, undrawn PET-coated ECCS samples (1 and 2). Typical spectra 
can be observed, which can be used as controls to distinguish the muscle adhesion on the polymer surface.

The spectra show some similarities but also different bands at the different spots indicating that the adhered salmon parts are different. These bands can be seen at $960 \mathrm{~cm}^{-1}, 1260 \mathrm{~cm}^{-1}, 1300 \mathrm{~cm}^{-1}, 1440 \mathrm{~cm}^{-1}$, and $1657 \mathrm{~cm}^{-1}$. The spectral plot shows the correlation between bands and adhered muscle and can therefore determine if the polymer surface has undergone any damage [17]. The above values indicated no significant effects on the polymer surface structure; however, it was possible to characterize the different areas of the samples. Nonetheless, band $960 \mathrm{~cm}^{-1}$ can be attributed to the symmetrical vibration of the phosphate group, possibly resulting from the contamination of salmon during the canning process. The spectra showed no evidence of any of the antibiotics under study. It is worth mentioning that the FT-IR Raman analysis distinguished the crystalline forms of the active chloramphenicol by its distinct bands at 859,389 , and $293 \mathrm{~cm}^{-1}$ [42].

Figure 10 shows bands at 970,1038, 1163, and $1536 \mathrm{~cm}^{-1}$ that were produced and identified in the samples but were not observed in the controls. The band width analysis shows important intensity differences in the spectral region 2700$3000 \mathrm{~cm}^{-1}$, corresponding to the $\nu(\mathrm{C}-\mathrm{H})$ vibrations associated with the detection of peptides $(\mathrm{C}-\mathrm{H})$ and represented by surface zones with reduced degradation. This is confirmed by the literature [43], which states that proteins can also be found at $1800-1500 \mathrm{~cm}^{-1}(\mathrm{C}=\mathrm{O}, \mathrm{N}-\mathrm{H}, \mathrm{C}-\mathrm{N})$ and in the region $500-1200 \mathrm{~cm}^{-1}$ composed by a mixture of proteins, lipids, and carbohydrates $(\mathrm{C}-\mathrm{O}, \mathrm{P}=\mathrm{O})$.

On the other hand, the FT-IR spectroscopy analyses did not detect the distinct ODS bands on the PET surface, in opposition to the results achieved with XPS; that is, bands at $2962 \mathrm{CH}_{3}-, 2924$, and $2854-\mathrm{CH}_{2}-$ in the spectral region $2800-3000 \mathrm{~cm}^{-1}$ were not detected [44]. The former can be explained by the performing features of each analysis; the FTIR analysis is performed at a depth of $5 \mu \mathrm{m}$ from the coating surface, whereas the XPS measurements are performed on the outermost atoms of the PET coating. The set of techniques used allowed us to discriminate and validate the effects of the salmon adhesion on the polymer coating.

The set of low-dimension tools employed in the characterizations and physicochemical analyses proved to have a great potential to determine the presence of antibiotics, contaminants, and compounds in water-enclosed environments occurring in aquaculture, intending to preserve food quality and keep the ecosystem free from such substances.

\section{Conclusions}

This study evaluated the adhesion of salmon to PET polymer coatings employed in canning processes in order to detect potential antibiotic residues after their application by the aquacultures industry. No detectable levels for the antibiotics tested were found. However, mass spectroscopy analyses detected traces of organic molecules, clearly distinguishing the presence of $\alpha$-carotene and oxidized cholesterol which can be naturally found in fish muscles like that of salmon.
We also determined the presence of peptides and proteins by mass spectrometry and electrophoresis in denaturing conditions (SDS-PAGE).

With the information shown above we have clearly concluded that organic molecules such as pigments (carotenoids), cholesterol, and proteins are bound to the polymer PET coating. These trace elements need to be further studied to determine their effects on the protective polymer.

The morphology characterization of the PET polymer in areas of salmon adhesion showed a homogeneous contact surface by scanning electron microscopy (SEM) observations; however, we confirmed that surface pores, roughness, or polymer microfolds favored adhesion of muscle proteins to the container.

A small percentage of muscle remains attached to the PET, evidencing stronger chemical bonds favored by the nanoscale roughness of the polymer surface, an aspect that contributes to the adherence as demonstrated by the AFM analyses showing phase changes with varying degrees of surface inclination.

Spectroscopy analyses showed the presence of PET, as well as salmon tissue adhered to the polymer surface. Areas with salmon adhesion or degraded surface showed small microstructural changes; the PET polymer with small traces of urea did not show the same crystallinity as revealed by the low Raman frequencies.

The FT-IR spectroscopy results characterized the presence and adhesion of salmon muscle to the polymer, the activity of the urea solution, and elucidated the conditions under which the adherence persisted, through the wavelength bands, after treatment with this solution.

\section{Conflict of Interests}

The authors declare that there is no conflict of interests regarding the publication of this paper.

\section{Acknowledgments}

The authors gratefully acknowledge Fondecyt Program of Conicyt Chile for the financial support through Grant no. 1130634 and the special contribution of University Austral of Chile.

\section{References}

[1] K. Grave and M. K. Hansen, "Previous and current trends in the usage of antimicrobial drugs in Norwegian aquaculture," 2009, http://www.fhi.no/dokumenter/ef83612534.pdf.

[2] K. Grave, V. F. Jensen, S. McEwen, and H. Kruse, "Monitoring of antimicrobial drug usage in animals: methods and applications," in Antimicrobial Resistance in Bacteria of Animal Origin, F. M. Aarestrup, Ed., pp. 375-395, ASM Press, Washington, DC, USA, 2006.

[3] P. Collignon, J. H. Powers, T. M. Chiller, A. Aidara-Kane, and F. M. Aarestrup, "World health organization ranking of antimicrobials according to their importance in human medicine: a critical step for developing risk management strategies for 
the use of antimicrobials in food production animals," Clinical Infectious Diseases, vol. 49, no. 1, pp. 132-141, 2009.

[4] O. E. Heuer, H. Kruse, K. Grave, P. Collignon, I. Karunasagar, and F. J. Angulo, "Human health consequences of use of antimicrobial agents in aquaculture," Clinical Infectious Diseases, vol. 49, no. 8, pp. 1248-1253, 2009.

[5] L. Burridge, J. S. Weis, F. Cabello, J. Pizarro, and K. Bostick, "Chemical use in salmon aquaculture: a review of current practices and possible environmental effects," Aquaculture, vol. 306, no. 1-4, pp. 7-23, 2010.

[6] K. Grave, E. Lingaas, M. Bangen, and M. Rønning, "Surveillance of the overall consumption of antibacterial drugs in humans, domestic animals and farmed fish in Norway in 1992 and 1996," Journal of Antimicrobial Chemotherapy, vol. 43, no. 2, pp. 243252, 1999.

[7] S. Suzuki and P. T. P. Hoa, "Distribution of quinolones, sulfonamides, tetracyclines in aquatic environment and antibiotic resistance in Indochina," Frontiers in Microbiology, vol. 3, article 67, 2012.

[8] FAO Fisheries and Aquaculture Department. Food and Agriculture Organization of the United Nations, The State of World Fisheries and Aquaculture, 2010.

[9] D. Tovar-Ramírez, D. Mazurais, J. F. Gatesoupe, P. Quazuguel, C. L. Cahu, and J. L. Zambonino-Infante, "Dietary probiotic live yeast modulates antioxidant enzyme activities and gene expression of sea bass (Dicentrarchus labrax) larvae," Aquaculture, vol. 300, no. 1-4, pp. 142-147, 2010.

[10] M. Mariscal-Arcas, A. Rivas, A. Granada, C. Monteagudo, M. A. Murcia, and F. Olea-Serrano, "Dietary exposure assessment of pregnant women to bisphenol-A from cans and microwave containers in Southern Spain," Food and Chemical Toxicology, vol. 47, no. 2, pp. 506-510, 2009.

[11] G. Choubert, F. Brisbarre, D. Parfouru, and M. Baccaunaud, "Argon modified atmosphere packaging for fillets of rainbow trout (Oncorhynchus mykiss) fed astaxanthin or canthaxanthin," Journal of Aquatic Food Product Technology, vol. 17, no. 2, pp. 117-136, 2008.

[12] A. S. Duun and T. Rustad, "Quality of superchilled vacuum packed Atlantic salmon (Salmo salar) fillets stored at -1.4 and $-3.6^{\circ}$ C, "Food Chemistry, vol. 106, no. 1, pp. 122-131, 2008.

[13] E. Zumelzu, F. Rull, C. Ortega, and C. Cabezas, "Effect of temperature on polyethylene teraphthalate coated eccs plates in acetic-acetate medium," Journal of Applied Polymer Science, vol. 113, no. 3, pp. 1853-1859, 2009.

[14] E. Zumelzu, F. Rull, and C. Ortega, "Titanium dioxide performance in polyethylene teraphthalate protective coatings on electrolytic chromium coated steels," Surface Engineering, vol. 25, no. 2, pp. 111-115, 2009.

[15] C. Schick, A. Wurm, and A. Mohammed, "Formation and disappearance of the rigid amorphous fraction in semicrystalline polymers revealed from frequency dependent heat capacity," Thermochimica Acta, vol. 396, no. 1-2, pp. 119-132, 2003.

[16] E. Zumelzu, C. Cabezas, and R. Alvarado, "Evaluation of the degradation of traditional and ECCS canning tinplates in acetic-acetate medium," Science and Engineering of Composite Materials, vol. 13, no. 1, pp. 13-19, 2006.

[17] E. Zumelzu, M. J. Wehrhahn, F. Rull, H. Pesenti, O. Muñoz, and R. Ugarte, "Evaluation of salmon adhesion on PET-metal interface by ATR, FT-IR, and raman spectroscopy," Journal of Spectroscopy, vol. 2015, Article ID 835798, 7 pages, 2015.

[18] A. Rodríguez, N. Carriles, J. M. Gallardo, and S. P. Aubourg, "Chemical changes during farmed coho salmon (Oncorhynchus kisutch) canning: effect of a preliminary chilled storage," Food Chemistry, vol. 112, no. 2, pp. 362-368, 2009.

[19] M. Mastromatteo, A. Danza, A. Conte, G. Muratore, and M. A. del Nobile, "Shelf life of ready to use peeled shrimps as affected by thymol essential oil and modified atmosphere packaging," International Journal of Food Microbiology, vol. 144, no. 2, pp. 250-256, 2010.

[20] Y. Byun, H. J. Bae, K. Cooksey, and S. Whiteside, "Comparison of the quality and storage stability of salmon packaged in various retort pouches," LWT-Food Science and Technology, vol. 43, no. 3, pp. 551-555, 2010.

[21] S. Bistac, M. F. Vallat, and J. Schultz, "Durability of steel/polymer adhesion in an aqueous environment," International Journal of Adhesion \& Adhesives, vol. 18, no. 5, pp. 365-369, 1998.

[22] H. D. Belitz and W. Grosch, Food Chemistry, Springer, Berlin, Germany, 2nd edition, 1999.

[23] I. Sommerset, B. Krossøy, E. Biering, and P. Frost, "Vaccines for fish in aquaculture," Expert Review of Vaccines, vol. 4, no. 1, pp. 89-101, 2005.

[24] J. V. Samsonova, A. Cannavan, and C. T. Elliott, "A critical review of screening methods for the detection of chloramphenicol, thiamphenicol, and florfenicol residues in foodstuffs," Critical Reviews in Analytical Chemistry, vol. 42, no. 1, pp. 5078, 2012.

[25] H. Gao, M. Matyka, B. Liu et al., "Intensive and extensive nitrogen loss from intertidal permeable sediments of the Wadden Sea," Limnology and Oceanography, vol. 57, no. 1, pp. 185-198, 2012.

[26] T. X. Le and Y. Munekage, "Residues of selected antibiotics in water and mud from shrimp ponds in mangrove areas in Viet Nam," Marine Pollution Bulletin, vol. 49, no. 11-12, pp. 922-929, 2004.

[27] V. Guillard, M. Mauricio-Iglesias, and N. Gontard, "Effect of novel food processing methods on packaging: structure, composition, and migration properties," Critical Reviews in Food Science and Nutrition, vol. 50, no. 10, pp. 969-988, 2010.

[28] A. He, S. Li, J. Ma, and Z. Yang, "Environmental friendly polymer materials for sustainable development," International Journal of Polymer Science, vol. 2014, Article ID 107028, 2 pages, 2014.

[29] V. Siracusa, "Food packaging permeability behaviour: a report," International Journal of Polymer Science, vol. 2012, Article ID 302029, 11 pages, 2012.

[30] M. Reid, "Food contact coatings," in Proceedings of the 8th International Tinplate Conference (ITRI '04), p. 25, The European Regulatory Environment, Paris, France, October 2004.

[31] T. Geens, L. Goeyens, and A. Covaci, "Are potential sources for human exposure to bisphenol-a overlooked?" International Journal of Hygiene and Environmental Health, vol. 214, no. 5, pp. 339-347, 2011.

[32] U. K. Laemmli, "Cleavage of structural proteins during the assembly of the head of bacteriophage T4," Nature, vol. 227, no. 5259, pp. 680-685, 1970.

[33] E. Zumelzu, I. Asomavich, C. Cabezas, C. Aguilar, and F. Rull, "Degradation of metal-polymer composite submitted to uniaxial deformations in $3.5 \% \mathrm{NaCl}$ solution," Journal of Adhesion Science and Technology, vol. 27, no. 8, pp. 939-950, 2013.

[34] NTIS, National Technical Information Service, USA, 2014, http://www.ntis.gov/about/.

[35] S. Ben Amor, M. Jacquet, P. Fioux, and M. Nardin, "XPS characterisation of plasma treated and zinc oxide coated PET," Applied Surface Science, vol. 255, no. 9, pp. 5052-5061, 2009. 
[36] F. Mistiri, K. Louati, O. Grissa, M. Kallel, and F. Safta, "Study of forced degradation behaviour of florfenicol by LC and LCMS and development of a validated stability-indicating assay method," Annales Pharmaceutiques Francaises, vol. 70, no. 6, pp. 333-347, 2012.

[37] R. Coyne, Ø. Bergh, and O. B. Samuelsen, “One-step liquid chromatographic method for the determination of oxytetracycline in fish muscle," Journal of Chromatography B: Analytical Technologies in the Biomedical and Life Sciences, vol. 810, no. 2, pp. 325-328, 2004.

[38] H. G. De Alwis, L. Girard, P. J. Kijak, and N. Rummel, "Determination of erythromycin in medicated salmonid fish feed by liquid chromatography and UV spectroscopy," Journal of AOAC International, vol. 96, no. 6, pp. 1233-1238, 2013.

[39] K.-I. Shozen, T. Ohshima, H. Ushio, A. Takiguchi, and C. Koizumi, "Effects of antioxidants and packing on cholesterol oxidation in processed anchovy during storage," LWT-Food Science and Technology, vol. 30, no. 1, pp. 2-8, 1997.

[40] Y. M. A. Naguib, "Antioxidant activities of astaxanthin and related carotenoids," Journal of Agricultural and Food Chemistry, vol. 48, no. 4, pp. 1150-1154, 2000.

[41] M. W. Ducey Jr., C. J. Orendorff, J. E. Pemberton, and L. C. Sander, "Structure-function relationships in high-density octadecylsilane stationary phases by Raman spectroscopy. 1. Effects of temperature, surface coverage, and preparation procedure," Analytical Chemistry, vol. 74, no. 21, pp. 5576-5584, 2002.

[42] M. C. Gamberini, C. Baraldi, A. Tinti, C. Rustichelli, V. Ferioli, and G. Gamberini, "Solid state characterization of chloramphenicol palmitate. Raman spectroscopy applied to pharmaceutical polymorphs," Journal of Molecular Structure, vol. 785, no. 1-3, pp. 216-224, 2006.

[43] J. L. R. Arrondo, A. Muga, J. Castresana, and F. M. Goñi, "Quantitative studies of the structure of proteins in solution by Fourier-transform infrared spectroscopy," Progress in Biophysics and Molecular Biology, vol. 59, no. 1, pp. 23-56, 1993.

[44] R. K. Iler and O. D. S. Raman, The Chemistry of Silica, Wiley, New York, NY, USA, 1979. 

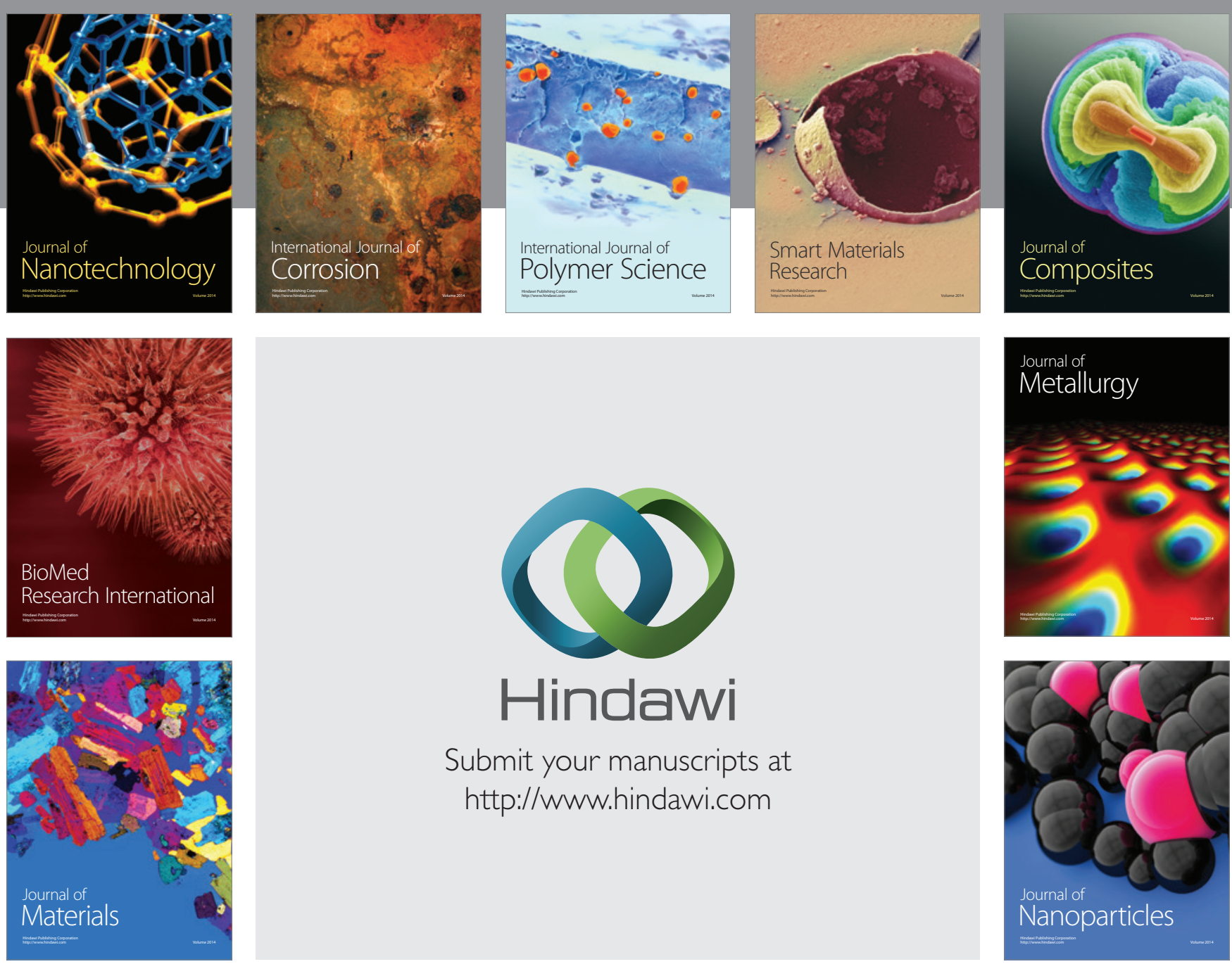

Submit your manuscripts at http://www.hindawi.com
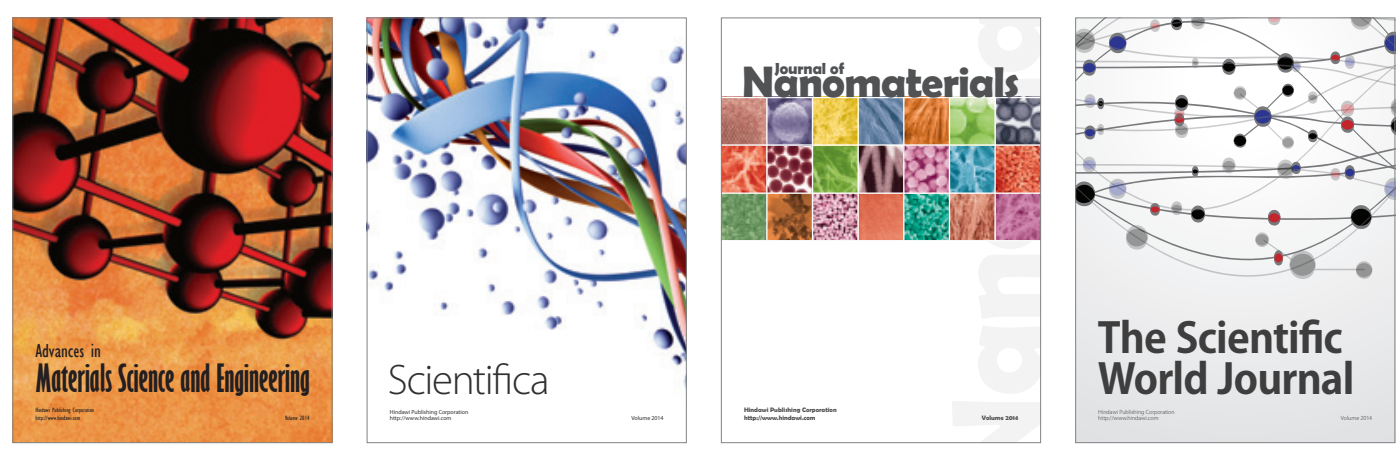

\section{The Scientific World Journal}
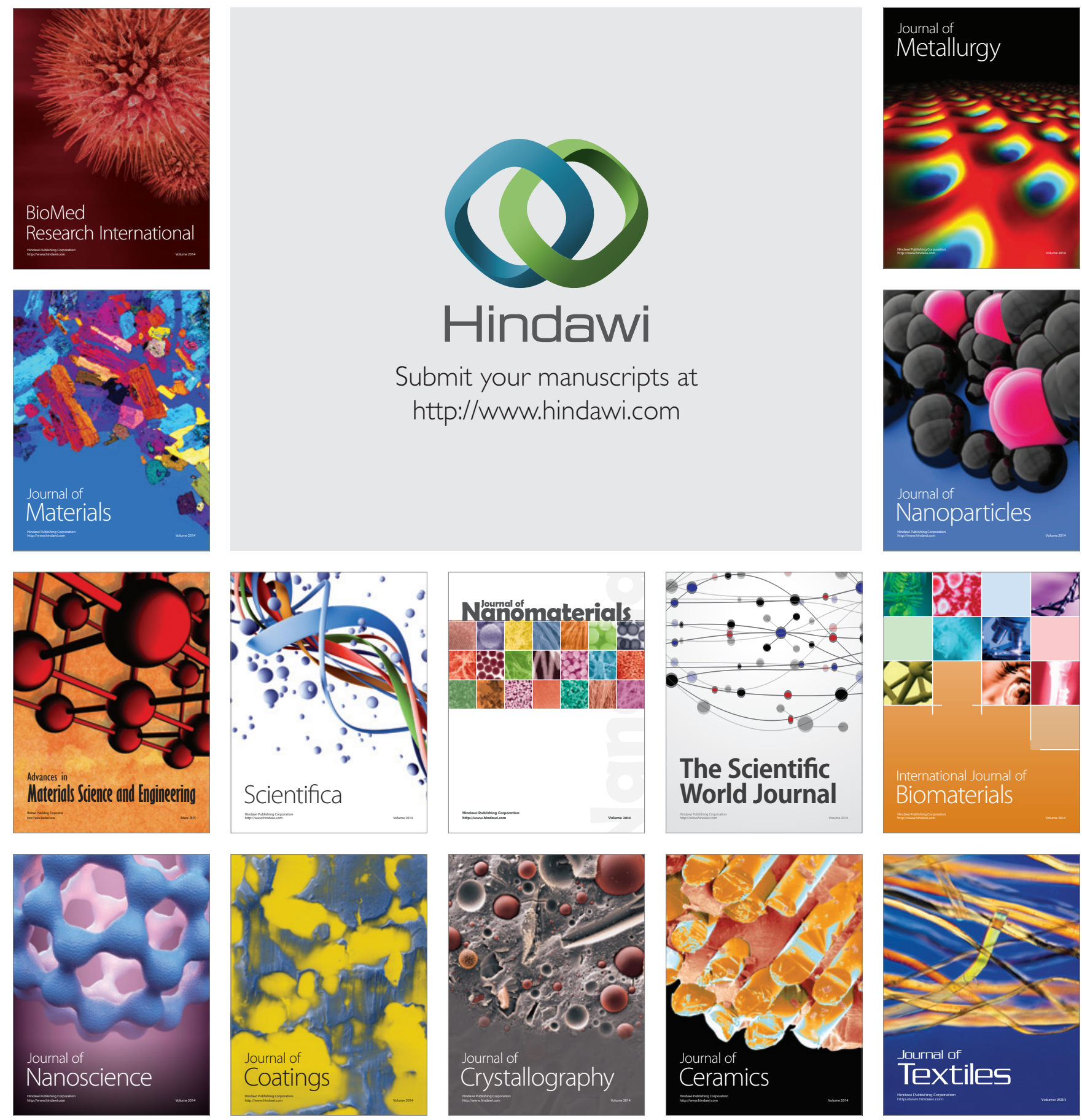